\title{
EDUCAÇÃO AMBIENTAL PARA SURDOS - ASJA VERDE: OFICINAS DAS ÁGUAS
}

\author{
Tabita Teixeira ${ }^{1}$ \\ Diego Fernando do Nascimento ${ }^{2}$ \\ Fernanda da Rocha Brando ${ }^{3}$
}

Resumo: O Projeto "ASJA VERDE" é uma iniciativa de Educação Ambiental que vem sendo realizada desde 2015 com surdos, amigos e intérpretes da Associação de Surdos de Jaú e Região (ASJA), em parceria com o Instituto Pró-Terra, ambos localizados no Município de Jaú/SP. Seu objetivo é o de promover a sensibilização e conscientização socioambiental junto com os surdos. Em 2018, foram realizadas seis "Oficinas das Águas" com um total de 26 horas e 20 participantes entre surdos e ouvintes. Nas oficinas foram trabalhadas e discutidas questões socioambientais relacionadas à água e a gestão compartilhada da água, tendo sido produzido ao final do processo vídeos de sensibilização e conscientização em Libras.

Palavras-chave: Educação Ambiental; Surdos; Libras; Água.

Abstract: The Deaf Association along with the Pro-Terra Institute from Jau have been promoting the ASJA VERDE project since 2015, which is an Environmental Education initiative. This project aimed to promote socio-environmental awareness and conscientization among deaf people, friends, and interpreters. Therefore, in 2018, six 'Water Workshops ' were organized in a total of 26 hours and 20 deaf and listeners participants. The topics discussed were mainly social-environmental water issues and shared water management, resulting in a Brazilian Sign Language (Libras) video production.

Keywords: Environmental Education; Deaf People; Brazilian Sign Language (Libras); Water.

\footnotetext{
${ }^{1} \mathrm{Tecg}^{\mathrm{a}}$ em Meio Ambiente e Recursos Hídrico - FATEC/JAHU, Especialista em Educação Ambiental para a Sustentabilidade, Mestra em Ciências pelo Programa de Pós-Graduação em Rede Nacional para o Ensino das Ciências Ambientais (PPG-PROFCIAMB) - USP/São Carlos. E-mail: tabitateixeira@gmail.com. Link para o Lattes: http://lattes.cnpq.br/7690269130882184

${ }^{2}$ Tecgo em Meio Ambiente e Recursos Hídrico - FATEC/JAHU, Licenciado em Ciências - USP/ Polo Jaú, Mestre em Ciências pelo PPG-PROFCIAMB - USP/São Carlos. E-mail: diegofernandodonascimento@gmail.com. Link para o Lattes: http://lattes.cnpq.br/75377577343331457

${ }^{3}$ Profä. do Departamento de Biologia da Faculdade de Filosofia, Ciências e Letras de Ribeirão Preto/USP e do PPG-PROFCIAMB - USP/São Carlos. E-mail: ferbrando@ffclrp.usp.br. Link para o Lattes: http://lattes.cnpq.br/0839314197501856
} 


\section{Introdução}

A água é um bem básico para a manutenção de toda a vida do planeta e direito fundamental para todos os povos. No entanto, as ações e atividades humanas vêm degradando e diminuindo sua qualidade, causando desequilíbrios ambientais, sociais e econômicos. Diante desse cenário, a participação da sociedade para a gestão compartilhada dos recursos hídricos é crucial para a sustentabilidade e para poder atender as presentes e futuras gerações.

Os processos de Educação Ambiental permitem a participação da população na superação dos problemas socioambientais enfrentados, por meio de ações organizadas e coletivas (SORRENTINO et al. 2005). Nesses processos devem ser considerados a realidade, o contexto histórico e político e a percepção ambiental de cada sujeito para que se torne um potencial ator/atriz multiplicador e transformador da realidade socioambiental que está inserido, assim como é previsto na Política Nacional de Educação Ambiental, Lei Federal no 9.795/1999 (BRASIL, 2008). Sendo assim, os coletivos como as comunidades surdas também devem passar por esses processos participativos, uma vez que suas formações sociais, culturais, experiências e sabedorias podem contribuir com a melhoria da gestão compartilhada das águas.

O trabalho relatado neste artigo trata-se de um projeto de Educação Ambiental realizado desde 2015 na Associação dos Surdos de Jaú e Região (ASJA), comunidade fundada em 19 de outubro de 1997 e considerada legalmente como uma entidade de utilidade pública de acordo com a Lei Municipal $n^{\circ}$ 3.257/1998. Além de realizar festas, campeonatos esportivos e viagens culturais, a ASJA possui diversos projetos de inclusão focados na legislação para os surdos, orientação para o mercado de trabalho, palestras e seminários, cursos de Libras e treinamento para intérpretes, apoio às associações de surdos vizinhas e atendimento e esclarecimento de dúvidas quanto à cultura surda (ASJA, 2018).

Em 2015, a Associação e o Instituto Pró-Terra desenvolveram em parceria uma intervenção participativa de Educação Ambiental que acabou se transformando no projeto chamado "ASJA VERDE". Dentre seus objetivos, destacaram-se a sensibilização e conscientização socioambiental dos participantes surdos, o trabalho com a cultura surda e a história regional dos associados e desenvolvimento de um Plano de Ações de Sustentabilidade da ASJA. Foram realizados 14 encontros ao longo do ano, entre saídas de campo, rodas de diálogos, dinâmicas, palestras e exposições (TEIXEIRA; CARAMANO, 2017).

Cabe destacar que os surdos tratados nesse estudo são usuários da Língua Brasileira de Sinais (Libras) - reconhecida pela Lei Federal no 10.436/2002 e regulamentada pelo Decreto no 5.296/2004 -, uma língua visualespacial completa que permite a comunicação e expressão por esses sujeitos por meio da utilização da visão e do espaço com movimentos das mãos, 
braços, corpo e expressões faciais (QUADROS; KARNOPP, 2004). Ela se difere da modalidade ouvinte oral-auditiva, na qual os ouvintes são aqueles que possuem a cultura da audição e comunicação por meio do oralismo (fala e escrita). Os associados também possuem como segunda língua o Português, sendo assim bilíngues (SOUSA, 2009), ou seja, comunicação da Libras de forma plena e leitura e escrita em Português.

Diante da urgência em se discutir a temática água e da continuidade ao projeto ASJA VERDE, em 2018 foram realizadas as Oficinas das Águas, contando novamente com a parceria do Instituto Pró-Terra e dessa vez com a USP - Polo de Jaú. Estas oficinas foram desenvolvidas entre os meses de Abril e Junho, totalizando seis encontros e tendo como participantes surdos e ouvintes entre 10 a 66 anos de idade.

O estudo fez parte de um mestrado profissional na área de Ensino de Ciências Ambientais intitulado "Material educomunicativo para o ensino de surdos: Educação Ambiental para as águas" (TEIXEIRA, 2019), sendo que o objetivo do presente artigo visa justamente mostrar como foram desenvolvidas as oficinas, tendo em vista que podem ser replicadas em outras associações e comunidades surdas, respeitando suas realidades e contextos em que estão inseridas.

\section{Metodologia}

Este estudo procurou incluir durante todo o seu processo o sujeito surdo, respeitando sua cultura, sua língua e singularidade de cada participante, a partir de suas vivências e olhares. Diante das experiências já realizadas ao longo desses anos no projeto e pelos resultados já alcançados, optou-se pelo uso de oficinas para introduzir e discutir a temática água em seu contexto socioambiental. Segundo Berned (2014), as oficinas possibilitam o processo de autoformação dos envolvidos uma vez que, tanto os participantes quanto o oficineiro, trocam ideias, saberes e vivências durante os diálogos, resultando num aprendizado coletivo através das próprias possibilidades e capacidades entre si e com os outros.

Cada uma das seis Oficinas das Águas possuiu seus próprios objetivos, envolvendo o conteúdo teórico programado (A água no ambiente natural, Água e sociedade e a Gestão compartilhada da água), a realização de atividades e a produção de materiais que ficaram expostos na ASJA. Para a elaboração e desenvolvimento dessas oficinas, foi utilizada como recurso pedagógico a pedagogia visual, por meio da perspectiva de Peres (2012), que utiliza recursos visuais didáticos para a produção do conhecimento. Diversas técnicas e instrumentos visuais foram utilizados ao longo das oficinas, tais como: apresentações de slides com imagens, fotos e gráficos, dinâmicas, maquetes, vídeos, arte-educação, experimentos, rodas de diálogos, saída de campo, entre outros. Cabe ressaltar que tal pedagogia se aplica para todas as pessoas, incluindo surdas e ouvintes. 
Toda a comunicação foi realizada por meio da Libras promovendo, dessa forma, a inclusão e a participação dos surdos durante todo o processo. A equipe técnica foi formada por uma educadora ambiental/oficineira habilitada em Libras; outro educador ambiental também conhecedor de Libras e que atuou como observador; uma estagiária do curso de Meio Ambiente e Recursos Hídricos e dois intérpretes tradutores de Libras que se revezaram ao longo dos encontros, auxiliando na comunicação entre a educadora ambiental e os participantes quando era preciso. $O$ registro do desenvolvimento das atividades foi feito por fotografias, filmagens de uma câmera e pelas anotações em um diário de campo.

O desenvolvimento do projeto em 2018 e o respectivo cronograma foram discutidos primeiramente em reuniões com a Diretoria da ASJA e apresentados aos demais associados em março do mesmo ano, no dia da Festa do Sorvete, sendo que 11 pessoas (entre surdos e ouvintes) aproveitaram a ocasião para se inscreveram. A divulgação do projeto contou com a colaboração da ASJA e do Instituto Pró-Terra, por meio de seus sites institucionais e pelas mídias sociais. Também foi divulgado no grupo "Projeto ASJA VERDE" da rede social Facebook, criado em 2015, onde foram adicionados os novos integrantes e as fotos tiradas ao longo das oficinas. $O$ grupo da "ASJA VERDE" foi criado no aplicativo WhatsApp para facilitar a comunicação entre os participantes e a equipe.

Assim, o projeto "ASJA VERDE" foi desenvolvido entre abril e junho de 2018, aos finais de semanas, sendo que a maioria dos encontros foi na própria sede da Associação e outros em espaços naturais da cidade de Jaú e nas instalações da USP Polo de Jaú. Ao final das oficinas foi realizada uma confraternização entre a equipe e os participantes para encerrar o projeto e receberem seus certificados.

\section{Ações e Discussões}

Ao todo participaram das Oficinas das Águas 20 pessoas na faixa etária dos 10 aos 66 anos, sendo 12 surdos (05 associados e 07 integrantes da Diretoria da ASJA) e 08 ouvintes (entre eles, 06 do Curso Intermediário de Libras), pertencentes aos municípios do Estado de São Paulo: Barra Bonita, Dois Córregos, Igaraçú do Tietê, Itapuí, Jaú e São Paulo (Quadro 1).

Quadro 1: Número de participantes nas Oficinas das Águas.

\begin{tabular}{|c|c|c|c|}
\hline \multicolumn{2}{|c|}{ Participantes } & № de Pessoas & Porcentagem (\%) \\
\hline \multirow{2}{*}{ Surdos } & Associados & 5 & 25 \\
\cline { 2 - 4 } & Diretoria & 7 & 35 \\
\hline \multirow{2}{*}{ Ouvintes } & Curso Intermediário de Libras & 6 & 30 \\
\cline { 2 - 4 } & Outros TOTAL & 2 & 10 \\
\hline \multicolumn{2}{|c}{ TO } & $\mathbf{1 0 0}$ \\
\hline
\end{tabular}

Fonte: Autoria própria. 
Cabe destacar que a participação em todas as oficinas não foi obrigatória portanto, a frequência variou ao longo dos encontros. Apesar de o projeto focar os surdos, a presença e a participação dos ouvintes foram importantíssimas para as oficinas, pois puderam vivenciar a cultura surda da Associação, contribuindo para a sua formação dentro da ASJA e também para a troca de visões e experiências entre surdos e ouvintes por meio da Libras. $\mathrm{Na}$ seção a seguir, serão relatadas as principais ações realizadas ao longo das oficinas.

\section{Oficinas das Águas}

As Oficinas das Águas tiveram em média 4 horas de duração cada, totalizando 26 horas, tendo 15 minutos de intervalo. Elas foram divididas em seis temáticas/encontros principais: A água na natureza, Bacia hidrográfica, Micro bacia Córrego dos Pires, Água e sociedade, Gestão compartilhada das águas e Produção de material de conscientização para as águas. A escolha dos finais de semanas para serem realizados os encontros atendia os participantes que moravam nos municípios vizinhos e que trabalhavam em horário comercial.

Para as Oficinas em particular, todos os presentes concordaram e assinaram o "Pacto das Águas", um pergaminho simbólico no qual constava que todos estavam se comprometendo com os dois últimos encontros a discutirem e buscarem soluções para os problemas relacionados às águas (em casa, em sua cidade e na ASJA), além de desenvolverem vídeos em Libras de conscientização sobre a importância da água para o canal da ASJA no YouTube e demais redes sociais da Associação. Esse Pacto ficou exposto ao longo das oficinas, enrolado dentro de uma garrafa de vidro com tampa de rolha.

A primeira Oficina foi realizada no dia 15 de abril com 05 participantes (04 surdos e 01 ouvinte). Foi abordada a temática água na natureza ressaltando seus aspectos físicos e químicos. Por meio de slides discutiu-se do que se tratava a água, como ela era encontrada na natureza, como surgiu no Planeta Terra, a quantidade de água salgada, doce e potável, seus estados físicos e propriedades químicas, a importância para os seres vivos, o ciclo hidrológico e algumas contaminações em rios. Alguns sinais novos também foram apresentados como, por exemplo, os de "molécula" e "átomo", os quais os participantes não conheciam.

Para compreenderem melhor o conteúdo teórico discutido, algumas ferramentas didáticas foram utilizadas, tais como: interação de modelos reduzidos de moléculas de água; experiências com a dissolução de produtos na água; construção de um cartaz com o corpo humano e a quantidade de água que cada órgão necessita; e confecção do ciclo da água em formas de cartões. Todas essas interações podem ser vistas na Fotografia 1. 

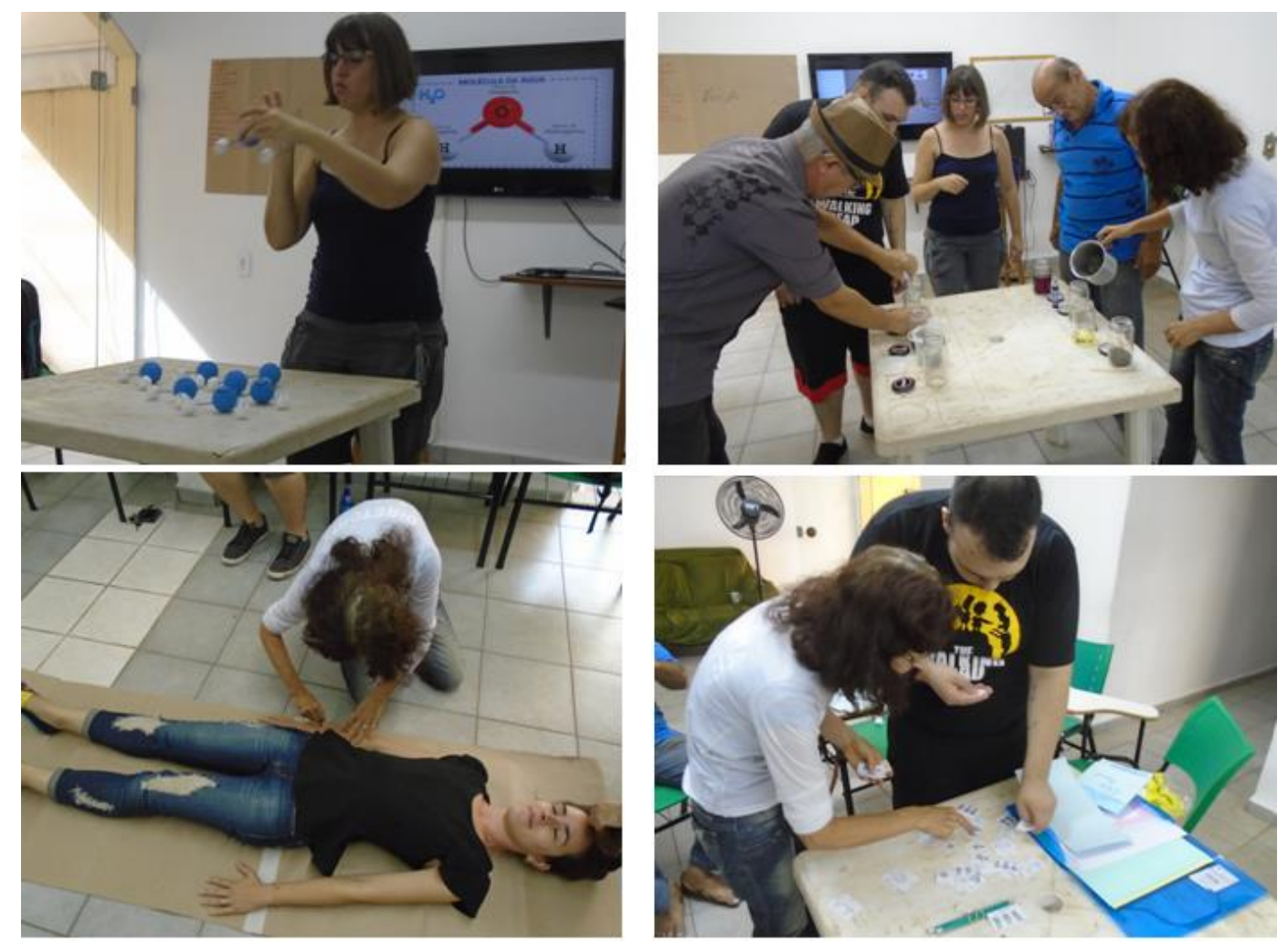

Fotografia 1: Demonstrações, experiências e atividades de arte-educação realizadas na $1^{\text {a }}$ Oficina.

Fonte: Ana Carolina Devite de Almeida Prado.

Em relação ao conteúdo, os participantes debateram mais sobre a quantidade de água em alguns seres vivos, pois a cada figura que era apresentada na tela eles remetiam às coisas de seu cotidiano ou à informações referentes à água, nem sempre relacionadas ao assunto proposto pelo slide. $\mathrm{A}$ experiência de misturar a água com outros elementos como areia, corante, folhas etc. foi o que eles mais se interessaram, pois gostaram de realizar os testes e verificar seus resultados.

A segunda Oficina foi realizada no dia 29 de abril tendo participado 12 pessoas (06 surdos e 06 ouvintes). A bacia hidrográfica foi abordada por meio de slides, discutindo sua composição desde a nascente até a foz, os ecossistemas aquáticos e terrestres que as compõem, a importância das matas ciliares (Bioma da Mata Atlântica), as bacias brasileiras, do Estado de São Paulo, da Unidade de Gerenciamento dos Recursos Hídricos - UGRHI ํㅜ 13, da sua sub-bacia do Rio Jaú e da micro bacia Córrego dos Pires, a qual a ASJA faz parte. Sinais foram retomados de etapas anteriores da ASJA VERDE como, por exemplo, o da "mata ciliar". Novos sinais foram discutidos e combinados de serem usados ao longo dos encontros, como "ecossistema" e "bacia hidrográfica".

Para facilitar o entendimento sobre o conteúdo, foi utilizada uma 
Terra; um vídeo com legendas em Libras contendo a fauna e flora encontradas em rios, oceanos e nas águas frias e profundas (desde organismos unicelulares até mais complexos); um modelo reduzido de mata ciliar feito com garrafa pet, mostrando o processo de assoreamento e erosão. Ainda, em grupo, foi finalizada uma maquete em escala real do Córrego dos Pires, onde os participantes tiveram que acrescentar as áreas urbanas, rurais e de vegetação natural com base na foto área do Córrego, pelo Google Maps. A Fotografia 2 mostra esses momentos.
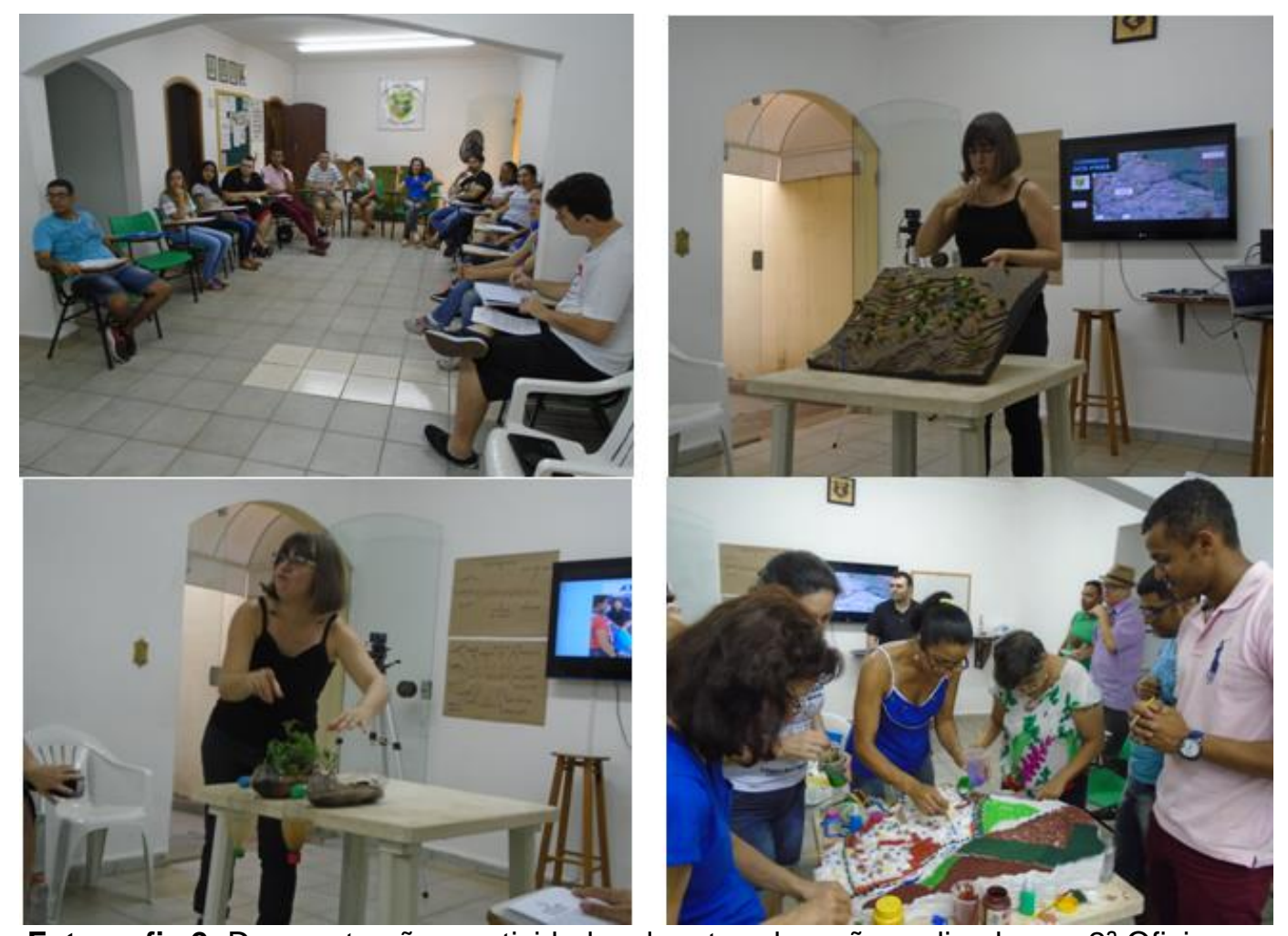

Fotografia 2: Demonstrações e atividades de arte-educação realizadas na $2^{\mathrm{a}}$ Oficina.

Fonte: Ana Carolina Devite de Almeida Prado.

O desenvolvimento da maquete foi o destaque da segunda Oficina, pois todos se envolveram em equipes para a sua produção. $O$ vídeo mostrado sobre os seres aquáticos causou muita conversa entre os participantes, à medida que algum animal ou planta eram apresentados pelos respectivos nomes em português, mas também discutidos pois já entendiam seus sinais.

Como o Córrego dos Pires foi a micro bacia escolhida para o estudo, nesta oficina foram repassadas informações sobre a saída de campo que ocorreria no próximo encontro, como data, horário e vestimentas adequadas.

A terceira Oficina foi realizada em 19 de maio e teve dois momentos: um no período da manhã com a saída de campo ao Córrego dos Pires e coleta de amostras de água e outro no período da tarde, na USP Polo de Jaú, com as observações das amostras em microscópios do laboratório. A princípio tinha se 
programado que os participantes conhecessem uma das três nascentes conservada da micro bacia, o Lago do Silvério (ambiente antrópico) e sua foz no Rio Jaú, coletando água nesses pontos para a atividade da tarde. No entanto, choveu no dia programado para a saída de campo, o que ocasionou o cancelamento da ida até a nascente, alterando a dinâmica da saída de campo.

No período da manhã compareceram 05 pessoas (03 surdos e 02 ouvintes). Como a chuva diminuíra um pouco, junto com o técnico do Instituto Pró-Terra foi planejada a ida dos participantes em torno da margem esquerda do Córrego (desde a nascente até a foz), por meio de uma van, onde foram discutidas algumas observações feitas pelos participantes. Para facilitar 0 entendimento sobre a localização, cada dupla recebeu um mapa impresso do Córrego dos Pires em papel A4, marcando os pontos de coleta de água. Durante o trajeto, foram mostrados os relevos limites da micro bacia, a mata ciliar, o escoamento superficial da água em lugares impermeáveis como os bairros próximos, os focos de queimadas e de presença de gado nas margens. Todas as ações provocadas pelo ser humano foram discutidas. Os participantes puderam tirar fotos e coletaram a água no Lago do Silvério e na foz da micro bacia. A Fotografia 3 mostra os momentos de observações e de coletas das águas.
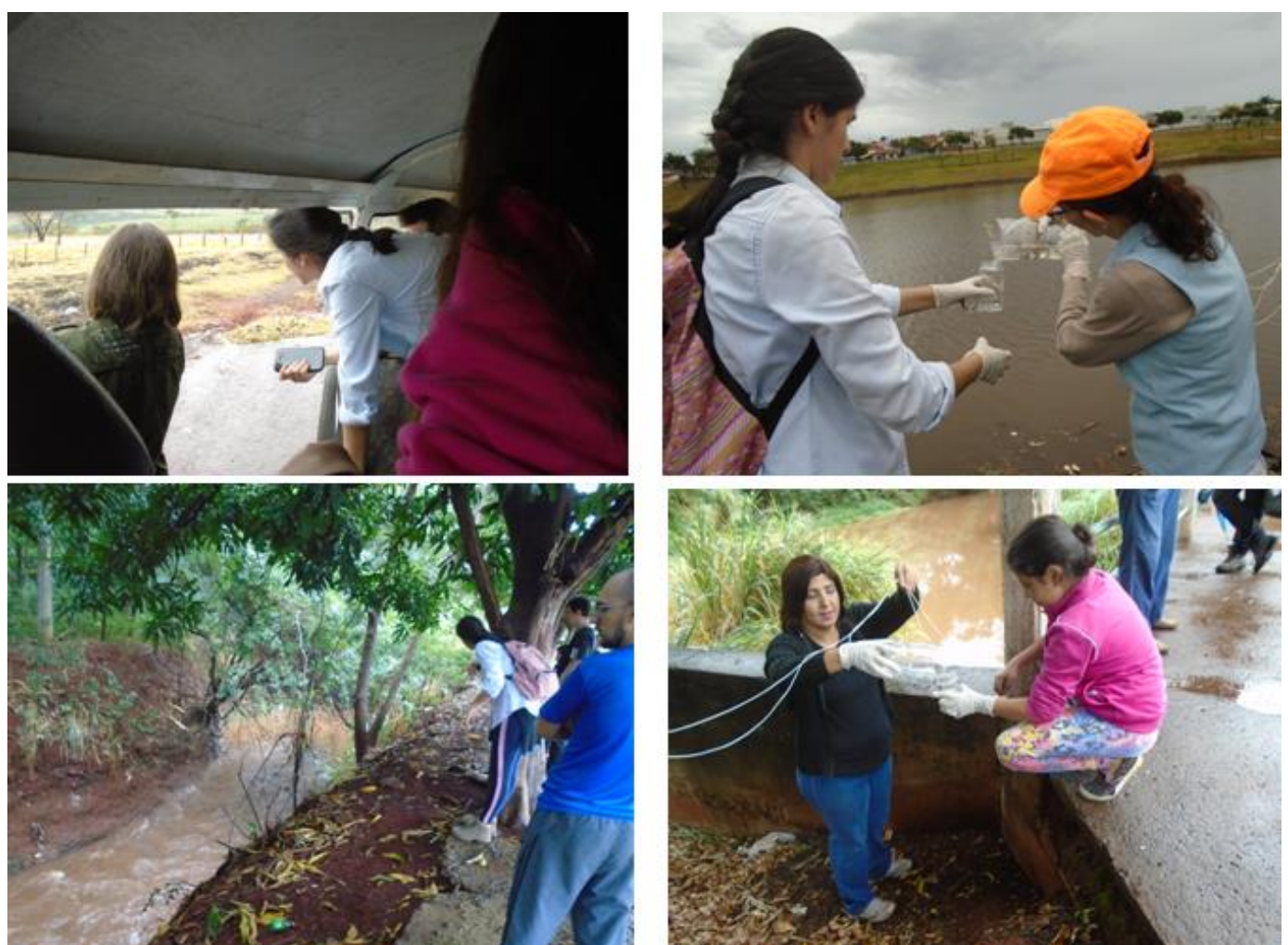

Fotografia 3: Saída de campo.

Fonte: Ana Carolina Devite de Almeida Prado. 
No período da tarde a chuva havia cessado, favorecendo o comparecimento de 10 participantes no laboratório da USP Polo de Jaú. Para as atividades, foram preparadas 06 amostras de água, sendo 02 do Lago do Silvério, 02 da foz e 02 da água da torneira do laboratório, e todas foram observadas em microscópios ópticos. Todos os participantes ficaram fascinados com a experiência e perguntavam como seria com outras substâncias, tais como sangue, refrigerante, entre outras. De fato, a maioria nunca tinha tido contato com um microscópio, sendo que os mais jovens relataram que já tinha visto em suas escolas.

Após as observações, todos se sentaram próximos a uma lousa, onde foi construído, em conjunto, um mapa mental do Córrego dos Pires, relembrando a atividade da manhã. Mapas mentais são ferramentas que permitem a reflexão e organização dos pensamentos, externalizando o que se passa mentalmente através de desenhos e escritas (BUZAN, 1996). Essa técnica também foi utilizada no final da Oficina 3, como forma de relembrar o que tinham visto e sintetizar essas informações. A princípio, interagiram mais em sua construção os participantes que foram na saída de campo pelo período da manhã. Mas, à medida que foram esclarecendo e identificando os pontos, os demais participantes contribuíram com esta construção, principalmente em relação ao Lago e a foz, por conhecerem esses lugares. A Fotografia 4 mostra os principais momentos do período da tarde da terceira Oficina.
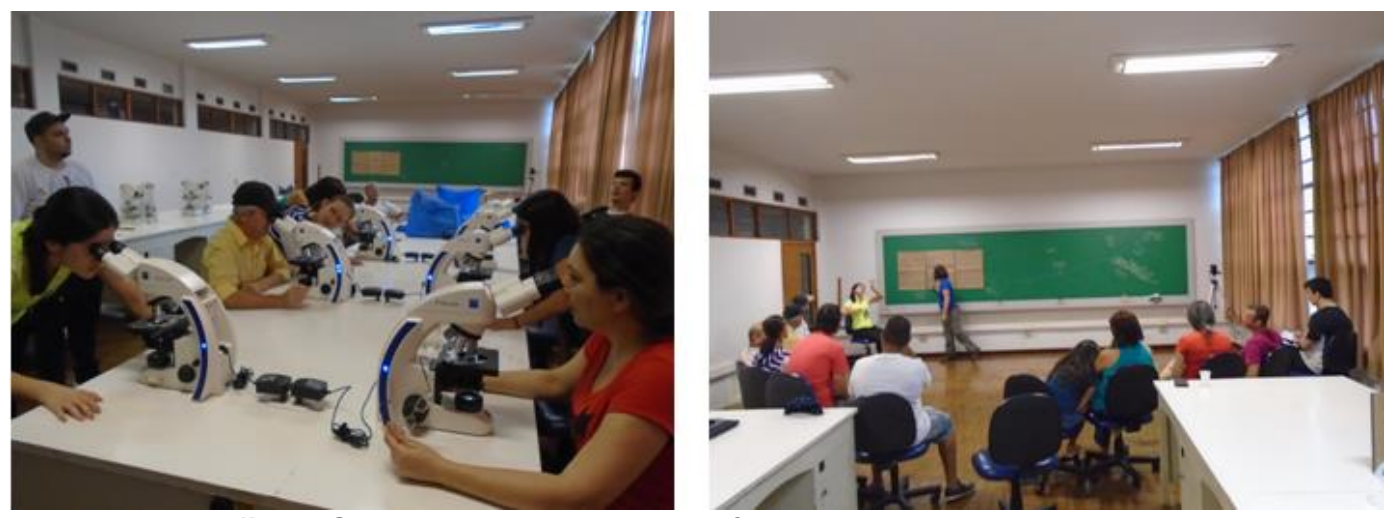

Fotografia 4: Observações nos microscópios e construção do mapa mental. Fonte: Ana Carolina Devite de Almeida Prado.

A quarta Oficina foi realizada no dia 3 de junho. Esse encontro foi remarcado devido à greve dos caminhoneiros que ocorreu, na época, em todo o país e interferiu na vinda de alguns dos participantes dos municípios vizinhos. Mesmo assim, no dia remarcado compareceram apenas 04 pessoas (03 surdos e 01 ouvinte). Nesta oficina foi discutido o uso da água pela sociedade, conteúdo apresentado por meio de slides mostrando seus usos ao longo das antigas civilizações, como Mesopotâmia, Egito, Grécia e Peru; os usos consuntivos e não consuntivos da água, sobre a água invisível/virtual e os gastos nas atividades industriais, rurais e urbanas no Brasil. Também foram discutidos formas de captação e tratamento da água e do esgoto, refletindo-se 
posteriormente em algumas formas de poluição e contaminação das águas e suas consequências para o meio ambiente e para o ser humano.

Para compreensão dos estudos foram utilizados como recursos visuais: um globo terrestre para encontrar os atuais países observados das antigas civilizações; a construção de uma pequena feira da água invisível, cujos produtos foram feitos em massinha e anotada a quantidade de água em litros consumida durante seu ciclo; uma animação interativa pela Internet sobre o tratamento de água (CARLETTO, 2018) e um vídeo de tratamento de esgoto legendado em português (VEOLIA, 2016); e uma dinâmica para os participantes adivinharem o tempo de decomposição dos resíduos lançados nos oceanos. A Fotografia 5 mostra alguns desses momentos interativos com os participantes.

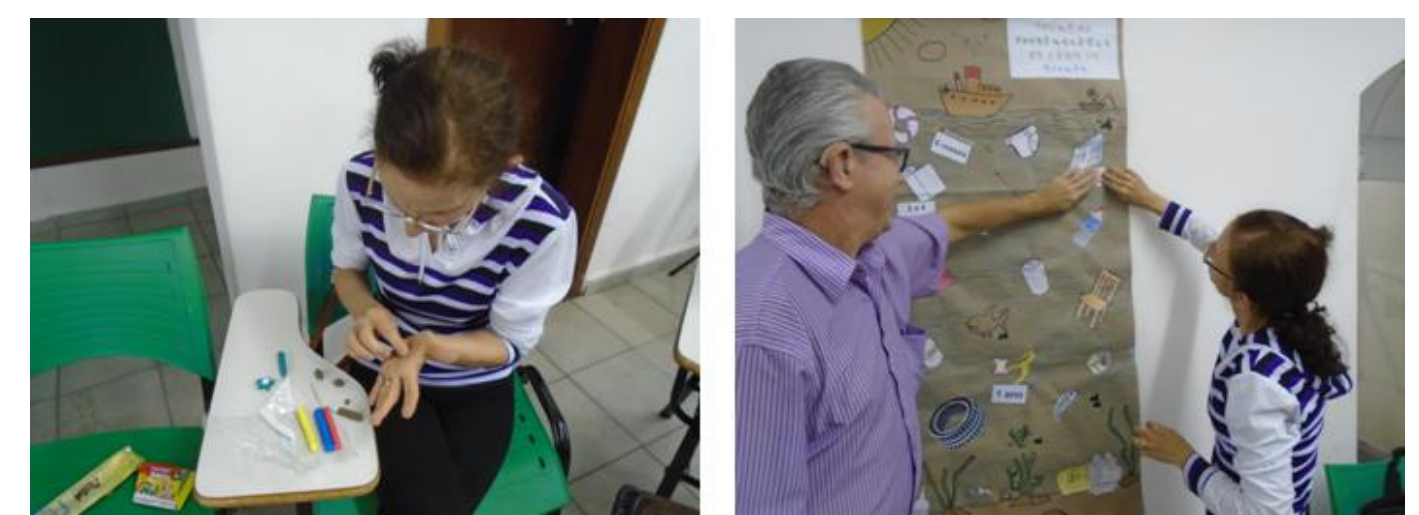

Fotografia 5: Produção da "Feira da Água Invisível" e dinâmica do tempo de decomposição dos resíduos.

Fonte: Ana Carolina Devite de Almeida Prado.

Nesta quarta Oficina os participantes interagiram mais com os assuntos voltados à poluição e contaminação das águas ao verem as fotos dos slides, assim como ficaram surpresos e interessados nos processos de tratamento da água e do esgoto.

A quinta Oficina foi realizada no dia 10 de junho, participando ao todo 05 pessoas (03 surdos e 03 ouvintes). O tema principal foi a gestão compartilhada das águas, sendo discutidos, por meio de slides, os seguintes assuntos: direitos e deveres que cada cidadão tem pela água, por meio da Declaração Universal dos Direitos da Água da ONU (BRASIL; MMA, 2000) e da Política Nacional de Recursos Hídricos, Lei no 9.433/97 (BRASIL, 2017); o consumo de água por diversos países e pelas regiões do Brasil; a relação entre a demanda e a disponibilidade de água no mundo; as responsabilidades pelos três setores - Poder Público (nível nacional, estadual e municipal), Usuários (indústrias e fazendas) e Comunidade (Instituições de ensino, ONGs, Associações e comunidades em gerais) -, além do mau uso da água e como este problema pode ser solucionado por tais setores. 
Para esta Oficina, inicialmente, foi apresentado e discutido um vídeo disponível no YouTube que tem como base a "Carta de 2070" (CRÓNICAS DE LOS TIEMPOS, 2012), interpretado em Libras pelo Intérprete. Posteriormente, foi realizada a dinâmica "Aquamóvel" (WWF-BRASIL, 2006), onde se é trabalhada a hipótese de um futuro sem água potável no Planeta Terra e a busca de novas fontes pelos países em outros planetas.

Ao final, foi aberto o Pacto das Águas, onde os participantes se dividiram para refletirem e discutirem os problemas em relação à água encontrados em suas casas, na ASJA e na sua cidade, além de proporem soluções para eles. Para reforçar e se preparem para a última Oficina, foi explicado como seria a atividade de produção do vídeo de conscientização sobre a água, mostrando como exemplo alguns vídeos em Libras disponíveis no YouTube. A Fotografia 6 mostra esses principais momentos.

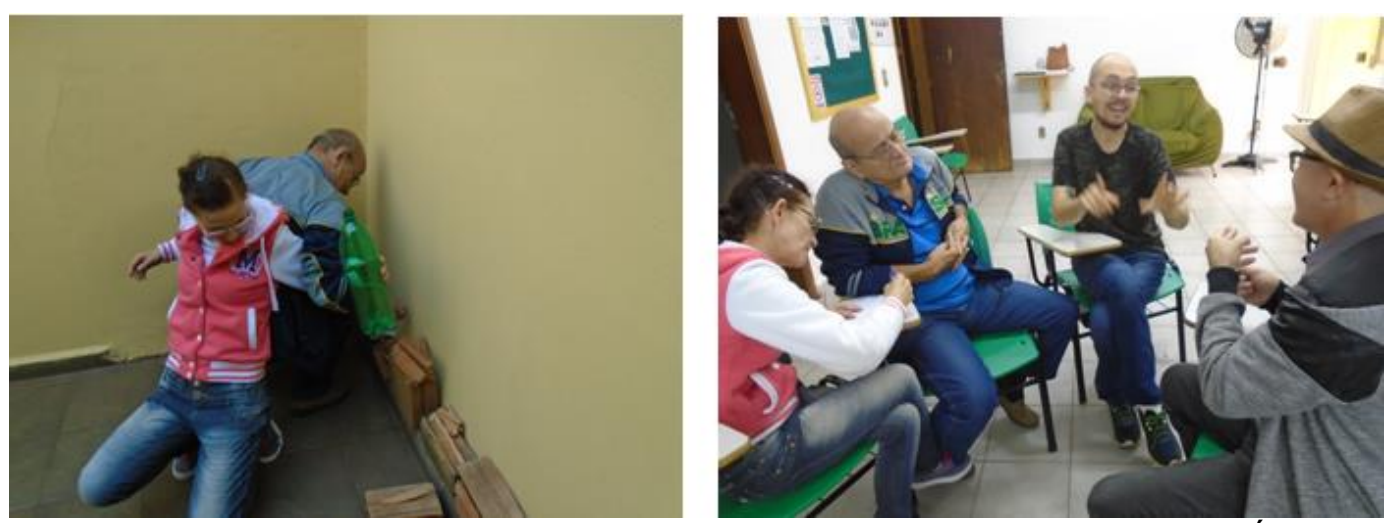

Fotografia 6: Dinâmica "Aquamóvel" e discussão sobre a atividade Pacto das Águas.

Fonte: Ana Carolina Devite de Almeida Prado.

Nesta Oficina, a "Carta de 2070" gerou importante debate, uma vez que os participantes se sensibilizaram e relacionaram suas ações de mau uso da água e de responsabilidades pela mesma, além de expressarem preocupação com um possível futuro sem água.

A sexta e última Oficina das Águas foi realizada no dia 24 de junho com 08 participantes (04 surdos e 04 ouvintes) e todos desenvolveram vídeos em Libras individualmente e um vídeo coletivo sobre a temática água. Seis pessoas haviam enviado seus vídeos pelo WhatsApp, apresentando aos presentes e discutindo seus conteúdos. Os roteiros desses vídeos foram transcritos com a ajuda de uma intérprete para facilitar as legendas que seriam inseridas posteriormente, na etapa de edição. Neste dia também foi realizada uma avaliação individual sobre o projeto desenvolvido no período. Após, foi elaborado coletivamente um novo roteiro, para o qual todos se organizaram, escolheram o local e participaram da filmagem. As preparações e a produção do último vídeo podem ser vistas na Fotografia 7. 

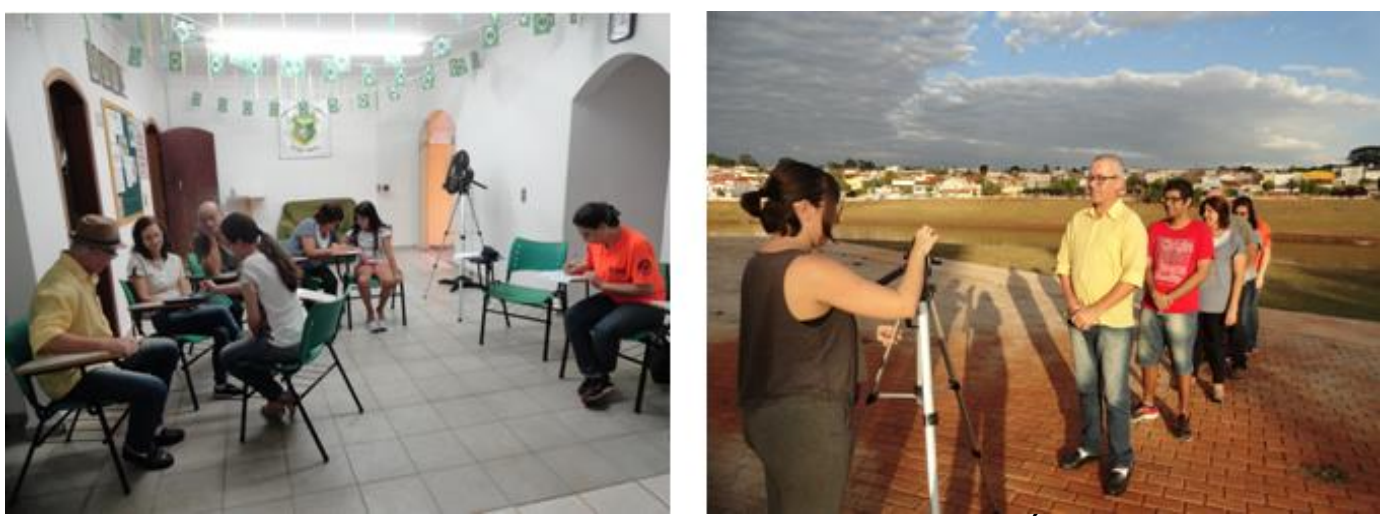

Fotografia 7: Produção dos vídeos do Pacto das Águas.

Fonte: Ana Carolina Devite de Almeida Prado.

Os vídeos foram editados, legendados em Português e aprovados pela Diretoria da ASJA no segundo semestre de 2018. Eles podem ser vistos pelo Facebook da ASJA: https://www.facebook.com/asja.jau/videos/asja-verde\%C3\%A1gua/310326673087201/ e também pelo canal de YouTube: https://www.youtube.com/watch?v=g9-UzdmpNpQ\&t=19s.

Para encerrar as Oficinas das Águas, foi realizada no dia 30 de junho uma confraternização com todos os participantes, a equipe técnica e amigos, totalizando 22 pessoas (09 surdos e 13 ouvintes). Todos os participantes receberam seus certificados e lembrancinhas das Oficinas (Fotografia 8).

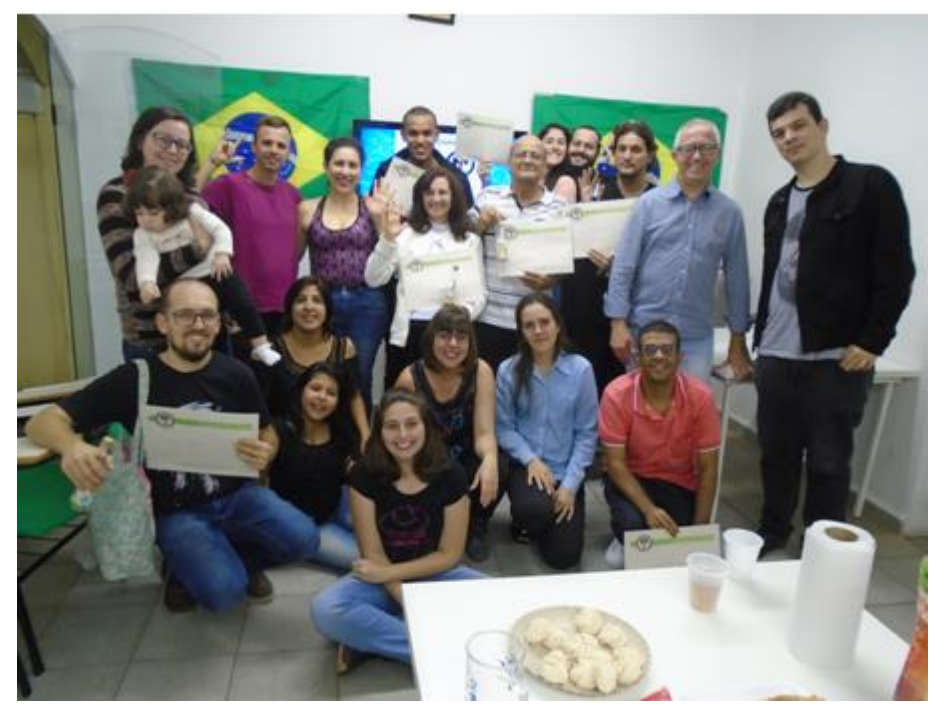

Fotografia 8: Participantes, amigos e equipe.

Fonte: Reginaldo Manoel dos Santos. 


\section{Avaliação das Oficinas das Águas}

Em relação às avaliações realizadas durante a sexta Oficina, cada participante respondeu em Libras as seguintes perguntas: "Você gostou das Oficinas das Águas? Por quê?", "Não gostou de algo? Por quê?", "Teve dificuldades em entender alguma coisa durante as oficinas? O que seria?", "Fale livremente sobre as oficinas". Todas as respostas foram filmadas e dentre seus depoimentos podemos destacar:

"Árvores bom, jogar lixo não pode, precisa limpar, recolher. Precisa rio cuidar, porque brincar não pode. Cuidar rio árvore importante. Cortar árvore não. Bom limpar ar, saúde. Precisa cuidar por causa futuro, banho chuveiro demora, lavar calçada gastar água. Pouca água usar, continuar futuro. Bom saúde, mundo. Arvores bom. Eu gosto ASJA VERDE." (Participante 5).

"Eu pergunta não entendia, explicava para mim, entendia, tudo clareava. Palavra conhece? Explicava curso, entendia. ASJA VERDE ensinava, importante, bom." (Participante 5).

"Minha opinião, muito bom aprender ASJA VERDE. Coisas importantes, precisa aprender surdo. Eu feliz." (Participante 15).

"Acho muito importante a gente conhecer sobre as oficinas e depois transmitir para os colegas de trabalho, para a família, acho que eu pude levar um pouquinho disso para os colegas de serviço, e para a família. Acho que eu pude explicar a ajudar a cuidar um pouco mais do meio ambiente, por causa da correria de trabalho não levamos em conta isso." (Participante 18).

A partir das falas, notou-se que entre os surdos, o cuidado com a contaminação dos recursos hídricos, com a mata ciliar e com o futuro do Planeta Terra foram os principais conteúdos que os preocuparam e que mais gostaram de discutirem. Tanto a avaliação quanto o acompanhamento das atividades realizadas ao longo das Oficinas mostraram que a metodologia empregada permitiu trabalhar a temática água junto aos surdos de forma crítica, promovendo o ensino e aprendizagem em grupo e a inclusão dos surdos quanto às informações socioambientais referentes à água.

\section{Considerações finais}

Dando continuidade às ações de Educação Ambiental do projeto ASJA VERDE, as Oficinas das Águas possibilitaram a troca de conhecimentos, de experiências e de olhares entre os participantes e a equipe técnica, a análise e reflexão dos conteúdos estudados sobre a água e a externalização de seus pensamentos e sentimentos por meio da arte-educação, das rodas de diálogo e de suas percepções ambientais. A importância da diversidade e de se ter diferentes faixas etárias dos participantes já tinham sidas observadas e 
mostradas nas primeiras oficinas em 2015 (TEIXEIRA; CARAMANO, 2017), onde a motivação dos jovens e as experiências dos adultos são valorizadas e compartilhadas entre eles.

Cabe destacar que apesar de não ter sido obrigatória a frequência, os participantes que não faltaram ou tiveram menos faltas aproveitaram mais essas experiências e compreenderam melhor a complexidade da temática água, pois as Oficinas foram construídas de forma sequencial e seus conteúdos se relacionavam entre si.

A discussão de novos sinais permitiu o enriquecimento do vocabulário e da ecoalfabetização dos participantes, pois não foram apenas inseridos/apresentados, e sim discutido o seu significado e o contexto que estava sendo inserido para poderem se apropriar daquele sinal e compreenderem sua complexidade, assim como as relações que ocorrem no meio ambiente. A promoção da Libras como forma de comunicação e de aprendizagem possibilitou a preservação e valorização da mesma e de se trabalhar os conceitos e termos socioambientais relacionados à água.

Todos os conteúdos das oficinas foram transformados em 06 vídeos educomunicativos em Libras, com legendas em português, como produtos do mestrado e disponibilizados no YouTube da ASJA: https://www.youtube.com/playlist?list=PLBTa9hw7Ca1-fy6GOkZD2W Oa9hGHhn1.

\section{Agradecimentos}

À Diretoria da ASJA por permitir a realização do projeto ASJA VERDE. A todos os participantes das Oficinas das Águas e associados surdos da ASJA. À equipe técnica do Instituto Pró-Terra, principalmente ao Binhão e à Ana Carolina, pelo apoio durante a realização das Oficinas. Aos intérpretes de Libras Adauto, Charlene e Janaina pelo auxílio no projeto. Ao pessoal da USP do Polo de Jaú pela parceria.

\section{Referências}

ASJA - Associação dos Surdos de Jaú e Região. História, Diretoria, Leis e Projetos. Disponível em: <https://www.asja.com.br/>. Acesso em: 8 out. 2018.

BRASIL. Lei no 10.436, de 24 de abril de 2002. Dispõe sobre a Língua Brasileira de Sinais - Libras e dá outras providências. Disponível em: <http://www.planalto.gov.br/ccivil 03/LEIS/2002/L10436.htm>. Acesso em: 10 set. 2017. 
BRASIL. Decreto no 5.626, de 22 de dezembro de 2005. Regulamenta a Lei № 10.436, de 24 de abril de 2002, que dispõe sobre a Língua Brasileira de Sinais - Libras, e o art. 18 da Lei № 10.098, de 19 de dezembro de 2000. Disponível em: <http://www.planalto.gov.br/ccivil 03/ ato20042006/2005/decreto/d5626.htm>. Acesso em: 29 out. 2017.

BRASIL. Lei no 9.795 de 27 de abril de 1999. Dispõe sobre a Educação Ambiental, institui a Política Nacional de Educação Ambiental e dá outras providências.

BRASIL. Lei no 9.433, de 8 de janeiro de 1997. Institui a Política Nacional de Recursos Hídricos e cria o Sistema Nacional de Gerenciamento de Recursos Hídricos. Disponível em: <http://www.planalto.gov.br/ccivil 03/leis/L9433.htm>. Acesso em: 22 nov. 2017.

BRASIL. Ministério do Meio Ambiente. Secretaria de Recursos Hídricos. Declaração Universal dos Direitos da Água. Porto Seguro: MMA/SRH, 2000 (Histore de L'eau, George Ifrah, Paris, 1992).

BERNED, I. da S. Oficinas: a criação de estratégias na educação de surdos. 2014. 104 f. Dissertação (Mestrado em Educação) - Universidade Federal de Santa Maria, Santa Maria, 2014. Disponível em: <https://repositorio.ufsm.br/bitstream/handle/1/7152/BERNED,\%20IGOR\%20D A\%20SILVEIRA.pdf?sequence $=1$ \&isAllowed $=y>$. Acesso em: 3 nov. 2018.

BUZAN, T. e B. The Mind Map Book. Plume, 2 ed., 1996.

CARLETTO, C. (Coor.). Como funciona uma estação de tratamento de água?.(?). Disponível em: <http://objetoseducacionais2.mec.gov.br/ bitstream/handle/mec/5035/open/file/index.html?sequence=8\&eventSource=2 $>$. Acesso em: 3 jun. 2018.

CRÓNICAS DE LOS TIEMPOS. Carta de 2070. 2012. Disponível em: <https://www.youtube.com/watch?v=VTc9UPtW2ts>. Acesso em: 10 jun. 2018.

PERES, D. L. A. A utilização da ilustração e da imagem artística na divulgação científica para surdos. 2012. 79 f. Dissertação (Mestrado em Química Biológica) - Instituto de Bioquímica Médica, Universidade Federal do Rio de Janeiro, Rio de Janeiro, 2012.

QUADROS, R. M. de; KARNOPP, L. B. Língua de sinais brasileira: estudos linguísticos. Porto Alegre: Artmed, 2004.

SORRENTINO, M.; TRAJBER, R.; MENDONÇA, P.; FERRARO Jr., L. A. Educação Ambiental como política pública. Educação e Pesquisa, São Paulo, v. 31, n. 2, p. 285-299, maio/ago, 2005.

SOUSA, A. N. de. The book is not on the table: o desenvolvimento da escrita de surdos em Língua Inglesa (LE). In: QUADROS, R. M. de; STUMPF, M. R. (Org.). Estudos Surdos IV. Petrópolis: Arara Azul, 2009. p. 206-241. 
TEIXEIRA, T. Material educomunicativo para o ensino de surdos: Educação Ambiental para as águas. 2019. 118f. Dissertação (Mestrado profissional em Ensino de Ciências Ambientais) - Programa de Pós-Graduação em Rede Nacional para o Ensino de Ciências Ambientais, Escola de Engenharia de São Carlos, Universidade de São Paulo: São Carlos, 2019. Disponível em: $<$ https://teses.usp.br/teses/disponiveis/18/18160/tde-20082019-

205809/es.php>. Acesso em: 15 out. 2019.

TEIXEIRA, T.; CARAMANO, A. ASJA Verde: intervenção participativa de Educação Ambiental na ASJA - Associação dos surdos de Jaú e região. REBEA - Revista Brasileira de Educação Ambiental, v. 12, n. 4, p. 221-241, 2017

VEOLIA. Coleta e tratamento de Águas Residuais. 2016. Disponível em: $<$ https://www.youtube.com/watch?v=bi2PD2HxrBQ>. Acesso em: 03 jun. 2018.

WWF-BRASIL. Cadernos de Educação Ambiental! Água para a vida, água para todos: livro das águas. Brasília: WWF- Brasil, 2006. 